\title{
Effect of nano sized transition metal salts and metals on thermal decomposition behavior of polyvinyl alcohol
}

\author{
Ranjana Singh ${ }^{1}$, S. G. Kulkarni ${ }^{1, *}$ and N. H. Naik ${ }^{2}$ \\ ${ }^{1}$ Department of Applied Chemistry, Defence Institute of Advanced Technology, Girinagar, Pune 411025, India \\ ${ }^{2}$ High Energy Materials Research Laboratory, Sutarwadi, Pune 411021, India
}

*Corresponding author. Tel: (+91) 20-24304160; Fax: (+91) 20-24389509; E-mail: sgk_iat1@rediffmail.com

\section{ABSTRACT}

A number of nanocomposites have been synthesized biomimetically by embedding various transition metal salts in polyvinyl alcohol (PVA) as the preorganised matrix. The metal salts were reduced to metallic form using aqueous sodium borohydride solution. In the present paper, very comprehensive studies on thermal decomposition behavior of these composites have been carried out using thermogravimetric and differential scanning calorimetric studies. The transition metal salts/ metals based composites exhibit increased thermal stability as indicated by shift in the decomposition temperature of pure PVA. The DSC data show increase in glass transition temperature of all composites, except the one containing iron, in comparison with neat PVA.The improvement in the thermal stability is explained in terms of decrease in the segmental mobility of polymer chains due to entrapment of metal salt / metal forming a complex with the hydroxyl group of the polymer chains and thus decreasing heat transfer process for decomposition of polymer composites. Copyright ( 2013 VBRI press.

Keywords: Polymer composites; preorganized matrix; decomposition temperature; glass transition temperature.

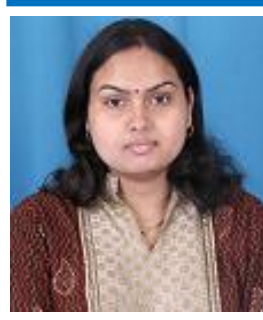

Ranjana Singh Ranjana Singh obtained her M.Sc degree in physical chemistry from University of Pune in the year 2006. She is presently working as senior research fellow and pursuing her $\mathrm{PhD}$ at Defence Institute of Advanced Technology, Pune under the supervision of Prof. S.G Kulkarni. Her areas of interest include polymer science, nanocomposites and high energy materials.

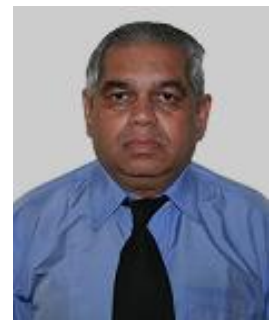

S. G Kulkarni is working as Professor at Defence Institute of Advanced Technology, Pune (India). He has vast experience of teaching at post graduate level and guided several M.Tech and $\mathrm{PhD}$ theses. He has published a number of research papers in national and international journals of repute and attended seminars / symposia / conferences and presented papers. His areas of interest include High energy materials, Detonics, NBC warfares, Energetic polymers and Nanocomposites. He has delivered a number of invited lectures at various universities, research establishments and ordnance factories in the

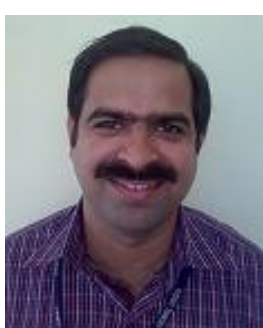
country.

N. H. Naik is working as Scientist at High Energy Materials Research Laboratory, Pune (India). He completed his Master of Science from University of Pune. He has published several research papers in International Journals and presented papers in conferences. His area of interest includes synthesis of nitrogen containing heterocycles, pyrolysis GCMS and thermal studies of high energy materials.

\section{Introduction}

In the recent years, a number of nanocomposites have been synthesized by various routes and characterized by different techniques for a wide variety of applications. Various non-conducting polymers like polyvinyl alcohol, polyethylene glycol (PEG), polypropylene glycol (PPG), polyvinyl acetate, polyvinyl chloride, polyethylene oxide, polyethylene terephthalate and conducting polymers like polyaniline, substituted polyanilines and polypyrrole have been extensively used for formulating composites [16].The different fillers or dopants like various transition metal salts, metal oxides, metal sulphides, metals, single / double hydroxides, clays and different types of carbon nanotubes [2-6] etc. in nano size have been used for formulation of nanocomposites and are reported in the literature. The nanocomposites find applications in various diverse fields such as electronics, optoelectronics, gas / humidity sensors, in batteries and fuel cells, electromagnetic shields, microwave absorbents etc. Among the various polymers mentioned above, PVA has been extensively used because of its availability with different molecular weights, its good film forming character, high hydrophilicity, processability, non-toxicity, 
biocompatibility, biodegradability and chemical resistance. In addition to all these advantages associated with PVA, it contains a carbon backbone with hydroxyl group attached to a methane carbon of each repeat unit which act as a source of hydrogen bonding and can possibly trap the metal ions or zero valent metals forming complexes. In the recent past, various transition metals like copper, cobalt, nickel, manganese, silver and their sulphides, oxides and salts have been doped in PVA to form composites[7-10]. The spectral, thermal and morphological characterizations of the composites have been carried out by the conventional techniques. Thermal stability of polymers and composites play an important role for some specific applications and can be enhanced by using appropriate fillers. In this paper thermal decomposition behavior of various transition metal salts and metals based composites have been extensively studied by thermogravimetric and differential scanning calorimetric analysis. Some of these composites find an application in gas / humidity sensors and ballistic armours. These fillers exhibit improvement in the thermal stability as realised by shift in thermal decomposition of pure PVA and glass transition temperature. Similar observations were made by various researchers [11-17].

\section{Experimental}

\section{Synthesis and characterization of polymer composites}

Polymer composites based on various transition metals like copper, cobalt, iron, cadmium and nickel were synthesized by using their salts as precursors in polyvinyl alcohol (PVA) as the preorganised matrix. Aqueous solution of PVA $(10 \%)$ was prepared by dissolving PVA in double deionised water at $90^{\circ} \mathrm{C}$. Solutions of metal salts were prepared at different concentrations ranging from 0.015 $0.045 \mathrm{M}$ in double deionised water at ambient temperature. Equal volumes of salt and PVA solution prepared earlier were mixed and continuously stirred for 2 hours at room temperature. It was then transferred to petri dishes and stainless steel trays and left in stainless steel processing chamber for 10 days under nitrogen flow at room temperature so as to dry by solvent loss. Dried samples were obtained in the form of films. The dried films were slowly heated at $60^{\circ} \mathrm{C}$ for six hours to remove the entrapped water, if any, and then cooled by immersing them in cold distilled water maintained at $10{ }^{\circ} \mathrm{C}$ to remove the metal salt adsorbed on the polymer surface. The polymer films were dried again at $60{ }^{\circ} \mathrm{C}$ for two hours and finally brought to room temperature. Dried PVA-metal salt films were characterized by different techniques and their mechanical properties were studied. Later on they were dipped into $0.1 \mathrm{M}$ aqueous solution of sodium borohydride maintained at $15^{\circ} \mathrm{C}$ for 30 minutes. During this period borohydride solution diffused into polymer film and reduced the metal ions to metallic state. As a result of reduction, the colour of the films changed from light blue to shinning brown in case of PVA-CuSO 4 and $\mathrm{PVA}-\mathrm{CuCl}_{2}$; light pink to black in case of $\mathrm{PVA}-\mathrm{CoCl}_{2}$ and PVA$\mathrm{Co}\left(\mathrm{CH}_{3} \mathrm{COO}\right)_{2}$; white to pale yellow in case of PVA$\mathrm{ZnCl}_{2}$ and PVA-CdSO 4 , reddish brown to black in case of $\mathrm{PVA}-\mathrm{Fe}\left(\mathrm{NO}_{3}\right)_{3}$ and $\mathrm{PVA}-\mathrm{FeCl}_{3}$. They were washed thoroughly with cold water to remove the sodium salt formed as a by-product of the reduction reaction and then with acetone. The composite films were dried in stainless steel processing chamber for two days to remove adhering water. Thermal decomposition behavior of the composites was studied by thermogravimetric (TGA) and differential scanning calorimetric (DSC) studies .TG studies were carried out in the temperature range of $30-600{ }^{\circ} \mathrm{C}$ in nitrogen atmosphere using Mettler Toledo; TGA 851e instrument keeping the heating rate of $20{ }^{\circ} \mathrm{C} / \mathrm{min}$ and nitrogen flow rate of $50 \mathrm{ml} / \mathrm{min}$. DSC studies were also carried out in the temperature range of $30-500{ }^{\circ} \mathrm{C}$ in nitrogen atmosphere maintaining nitrogen flow rate of 50 $\mathrm{ml} / \mathrm{min}$.

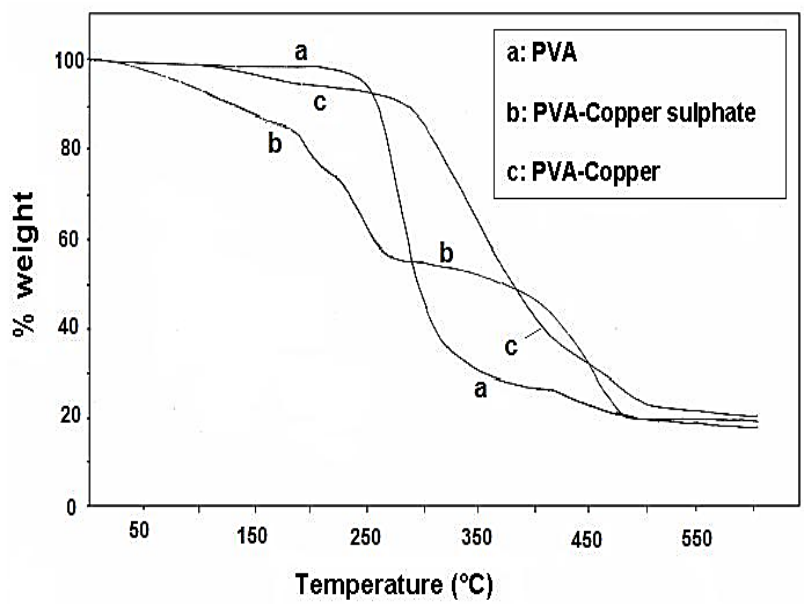

Fig. 1. TG curves for a) PVA, b) PVA-copper sulphate composite, c) PVA-copper composite.

\section{Results and discussion}

The thermograms were recorded for pure PVA and for various composites prepared by embedding different transition metal salts and metals. Fig 1 shows the TGA curve of pure PVA and PVA doped with copper sulphate and copper. From TGA curve it is clear that PVA starts decomposing at its melting temperature of $220^{\circ} \mathrm{C}$ with continuous weight loss up to $400^{\circ} \mathrm{C}$ exhibiting around $75.2 \%$ weight loss. From $400-500^{\circ} \mathrm{C}$, there is gradual decomposition with $8.3 \%$ weight loss. After $510^{\circ} \mathrm{C}$ onwards, a plateau region exhibiting constant weight (around 15\%) is seen in the TG curve. The initial weight (around 2\%) loss may be due to degradation of large polymer chains into small fragments which subsequently undergo further decomposition forming carbonaceous matter at around $500{ }^{\circ} \mathrm{C}$ and remains constant thereafter showing the plateau behavior. Similar observations were made by other workers [17]. The Table 1 includes temperature ranges for different decomposition stages along with percentage weight loss for pure PVA and composites synthesized using various metal salts of 0.045 molar concentration like copper sulphate pentahydrate, copper chloride anhydrous, cobalt chloride hexahydrate, cobalt acetate tertahydrate, ferric chloride hexahydrate, ferric nitrate nonahydrate, cadmium sulphatedihydrate and nickel nitrate hexahydrate and for composites obtained after in situ reduction of these metal salts in the matrix. 
Copper sulphate doped PVA composite, exhibits four stage decomposition unlike PVA with different decomposition patterns as shown in figure 1.Initial weight loss of around $13.4 \%$ in the temperature range of $30-177^{\circ} \mathrm{C}$ may be due to formation of copper sulphate trihydrate at about $110^{\circ} \mathrm{C}$ which gradually gets converted into monohydrate at about $225^{\circ} \mathrm{C}$. The third stage decomposition in the temperature range of $226-300^{\circ} \mathrm{C}$ showing around $20 \%$ weight loss may be due to pure PVA in presence of partially dehydrated copper sulphate indicating the marginal increase in decomposition temperature of PVA present in the composites. PVA undergoes further decomposition at $300^{\circ} \mathrm{C}$ in presence of anhydrous copper sulphate forming copper oxide at around $540^{\circ} \mathrm{C}$. After this temperature it shows constant weight (around $2.5 \%$ ) which might be due to copper oxide and some carbonaceous matter. This is in agreement with the reported information on the thermal decomposition behavior of pure copper sulphate pentahydrate[18].

Table 1. TG data of PVA based composites.

\begin{tabular}{|c|c|c|}
\hline $\begin{array}{l}\text { Polymer and } \\
\text { metal salts* / } \\
\text { metals }\end{array}$ & $\begin{array}{l}\text { Decomposition } \\
\text { temp. range }\left({ }^{\circ} \mathbf{C}\right)\end{array}$ & $\begin{array}{l}\text { \% Weight } \\
\text { loss }\end{array}$ \\
\hline \multirow[t]{2}{*}{ PVA } & $220.25-400$ & 75.20 \\
\hline & $400-517.02$ & 8.33 \\
\hline \multirow{4}{*}{$\begin{array}{l}\mathrm{PVA}+ \\
\mathrm{CuSO}_{4} 5 \mathrm{H}_{2} \mathrm{O}\end{array}$} & $35.69-177.61$ & 13.42 \\
\hline & $177.03-225.90$ & 10.69 \\
\hline & $225.32-299.65$ & 19.62 \\
\hline & $300.22-539.32$ & 34.80 \\
\hline \multirow[t]{3}{*}{$\mathrm{PVA}+\mathrm{Cu}$} & $116.44-235.11$ & 5.34 \\
\hline & $234.55-429.52$ & 65.88 \\
\hline & $428.79-553.71$ & 14.75 \\
\hline \multirow[t]{2}{*}{$\mathrm{PVA}+\mathrm{CuCl}_{2}$} & $230.71-296.18$ & 24.50 \\
\hline & 296.18- 510.49 & 54.90 \\
\hline \multirow[t]{2}{*}{$\mathrm{PVA}+\mathrm{Cu}$} & $215.42-402.01$ & 74.43 \\
\hline & $401.44-513.98$ & 11.64 \\
\hline
\end{tabular}

\begin{tabular}{lll}
\hline $\begin{array}{l}\text { Polymer and } \\
\text { metal salts* } / \\
\text { metals }\end{array}$ & $\begin{array}{l}\text { Decomposition } \\
\text { temp. range }\left({ }^{\circ} \mathrm{C}\right)\end{array}$ & $\begin{array}{l}\% \text { weight } \\
\text { loss }\end{array}$ \\
\hline
\end{tabular}

metals

$\mathrm{PVA}+$ $86.50-231.79 \quad 8.98$

$\mathrm{CoCl}_{2 .} 6 \mathrm{H}_{2} 0$

$231.03-340.66 \quad 38.71$

$340.66-544.27 \quad 30.20$

$\mathrm{PVA}+$

$36.37-214.89$

12.04

$\mathrm{Co}\left(\mathrm{CH}_{3} \mathrm{COO}\right)_{2} \cdot 2$

$\mathrm{H}_{2} \mathrm{O}$

213.76-357.61 $\quad 66.05$

$357.03-523.08$

10.62

$\mathrm{PVA}+\mathrm{Co}$

35.37-174.35

7.82

227.13-364.76

64.71

364.76-510.30

11.27

PVA +

$37.81-250.27$

12.07

$\mathrm{FeCl}_{3} \cdot 6 \mathrm{H}_{2} \mathrm{O}$

$250.27-354.91$

55.90

$353.78-537.09$

17.42

$\mathrm{PVA}+\mathrm{Fe}$

218.65-344.40

55.85

344.40-521.92

23.41

$\mathrm{PVA}+$

35.01- 219.65

7.08

$\mathrm{Fe}\left(\mathrm{NO}_{3}\right)_{3} \cdot 9 \mathrm{H}_{2} \mathrm{O}$

$219.65-377.96$

67.33

$377.96-507.05$

14.29

$\mathrm{PVA}+\mathrm{Fe}$

$107.72-252.68$

7.08

$255.05-391.51$

67.33

$377.96-507.05$

14.29

PVA+

70.24-246.10

12.60

$\mathrm{CdSO}_{4} \cdot 2 \mathrm{H}_{2} \mathrm{O}$

245.36-372.07

57.79

372.07-531.70

19.97 


\begin{tabular}{lll}
$\begin{array}{l}\text { Polymer and } \\
\text { metal salts* } / \\
\text { metals }\end{array}$ & $\begin{array}{l}\text { Decomposition } \\
\text { temp. range }\left({ }^{\circ} \mathrm{C}\right)\end{array}$ & $\begin{array}{l}\% \text { weight } \\
\text { loss }\end{array}$ \\
\hline
\end{tabular}

$\mathrm{PVA}+\mathrm{Cd}$

43.03-214.76

$223.97-376.37$

$376.37-526.87$

$\mathrm{PVA}+\mathrm{Ni}$

205.49-355.16

$355.51-525.57$

12.71

* Concentration of metal salts was $0.045 \mathrm{M}$ while formulating composites

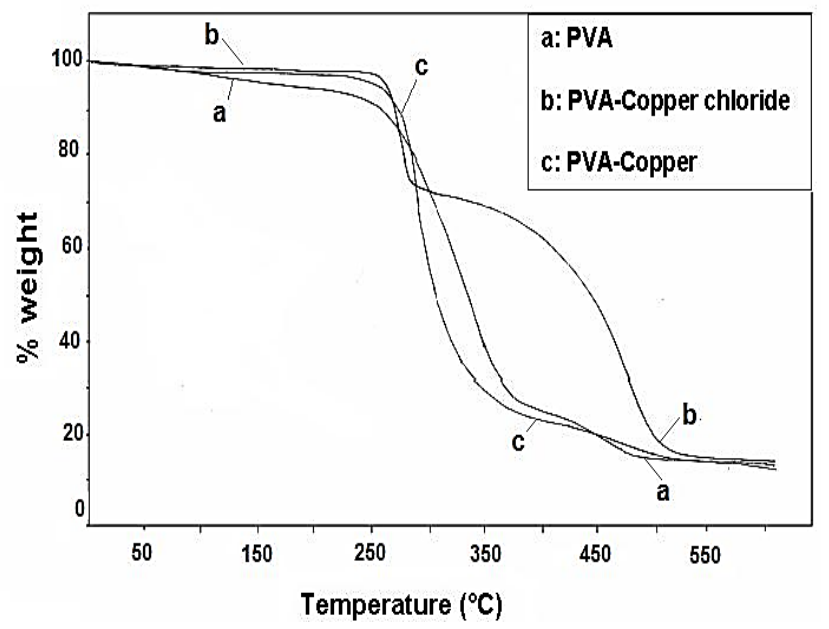

Fig. 2. TG curves for a) PVA, b) PVA-copper chloride composite, c) PVA-copper composite.

When copper sulphate is reduced to metallic copper in the polymer matrix, the composite formed exhibited three stage decomposition. The initial decomposition exhibits around $5 \%$ weight loss in the temperature range of $116^{\circ} \mathrm{C}$ to $235{ }^{\circ} \mathrm{C}$ may be due to adsorbed moisture. The decomposition temperature of PVA gets shifted to $235^{\circ} \mathrm{C}$ and shows continuous degradation up to $430^{\circ} \mathrm{C}$ with around $65 \%$ weight loss. The slow degradation further continues up to $550{ }^{\circ} \mathrm{C}$ with $14.7 \%$ weight loss. Thereafter a constant weight around $15 \%$ is realised.This may be partly due to carbanecous mass and copper. From the above observation it is clear that the presence of copper sulfate or copper in PVA significantly affects the decomposition pattern of PVA and marginally increases the decomposition temperature of PVA (Fig. 1).

The copper chloride PVA based nanocomposite shows two stage decomposition as seen in Fig. 2. The copper chloride being anhydrous salt does not show weight loss up to $230^{\circ} \mathrm{C}$ and start decomposing at that temperature with sharp weight loss up to $296{ }^{\circ} \mathrm{C}$ and later on slow but continuous weight loss up to $500{ }^{\circ} \mathrm{C}$. Thereafter a constant weight around $19 \%$ is realised which may be partly due to carbanecous mass and partly due to copper oxide. It is clear from the TGA curve that the decomposition of PVA after $296{ }^{\circ} \mathrm{C}$ gets affected because of presence of cupric chloride which may start decomposing after $300{ }^{\circ} \mathrm{C}$ along with
PVA. The $\%$ weight loss at $400{ }^{\circ} \mathrm{C}$ at the end of first stage decomposition for pure PVA is $76 \%$. The $\%$ weight loss at the same temperature for copper sulphate and copper chloride based composites was found to be around 52\% and $40 \%$ respectively exhibiting increased thermal stability of composites in comparison with pure PVA. When PVAcopper sulphate and PVA-copper chloride based composites were reduced to metallic copper exhibited 65.6 $\%$ and $78 \%$ weight loss respectively at $400^{\circ} \mathrm{C}$. This indicates that copper salts impart more thermal stability than zero valent copper embedded in the polymer matrix .Within the copper salts, copper chloride imparts more thermal stability than copper sulphate as indicated by percentage weight loss at $400{ }^{\circ} \mathrm{C}$ for both the composites.

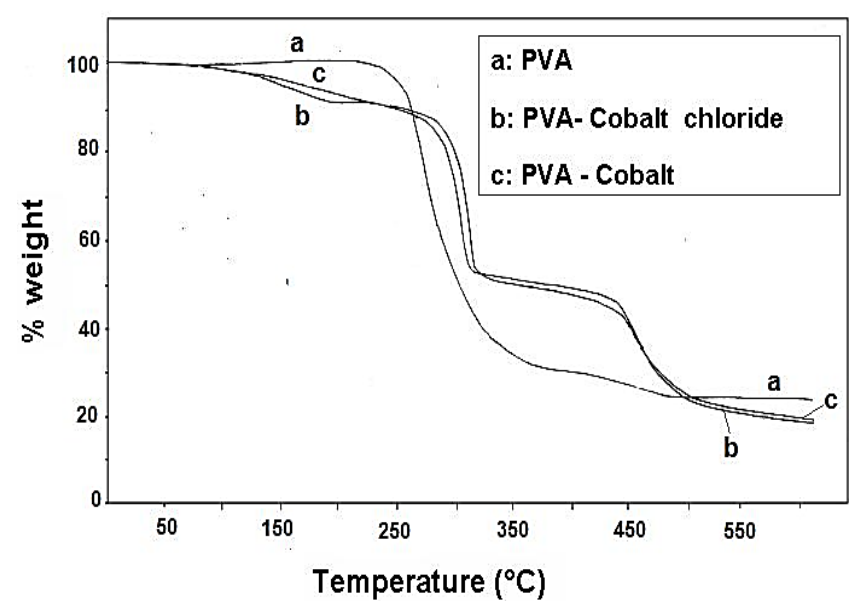

Fig. 3. TG curves for a) PVA, b) PVA-cobalt chloride composite, c) PVAcobalt composite.

Cobalt chloride hexahydrate based composite shows three stage decomposition. Fig. 3 includes TG curves for cobalt chloride, cobalt based composites and neat PVA. Table 1 includes the decomposition temperature for various stages along with percentage weight loss. Initial weight loss at $231^{\circ} \mathrm{C}$ (around 9\%) may be due to dehydration of the salt or loss of water of crystallization. Second stage decomposition starts around $231{ }^{\circ} \mathrm{C}$ and shows continuous degradation up to $340{ }^{\circ} \mathrm{C}$ with around $38.7 \%$ weight loss. The decomposition behavior of PVA thus gets affected due to presence of anhydrous cobalt chloride. After $340^{\circ} \mathrm{C}$, it shows a gradual weight loss up to $435^{\circ} \mathrm{C}$ and rapid weight loss thereafter up to $544{ }^{\circ} \mathrm{C}$ with $30 \%$ weight loss. After $550^{\circ} \mathrm{C}$ onwards, a constant weight around $22 \%$ is realized. It is due to cobalt oxide and some carbonaceous mass from PVA. Metallic cobalt based composite shows however similar decomposition behavior like that of cobalt chloride based composite but with change in the decomposition temperature. The first stage decomposition ends at $257{ }^{\circ} \mathrm{C}$ with around $8.4 \%$ weight loss comparable to that shown by cobalt chloride based composite. However, the second stage decomposition temperature shifts from $231.8{ }^{\circ} \mathrm{C}$ to $257^{\circ} \mathrm{C}$ and ends at $354{ }^{\circ} \mathrm{C}$ exhibiting around $41 \%$ weight loss during second stage of decomposition. The third stage decomposition starts from $354^{\circ} \mathrm{C}$ and shows gradual weight loss up to $435{ }^{\circ} \mathrm{C}$ and rapid weight loss thereafter up to 544 ${ }^{\circ} \mathrm{C}$ with around $30 \%$ weight loss similar to that as noticed in the case of cobalt chloride based composite. Thus, the 
decomposition patterns in the second and third stages of decomposition practically remain the same for cobalt chloride and cobalt based composites. After $550^{\circ} \mathrm{C}$ onwards a constant weight around $13 \%$ is realised.

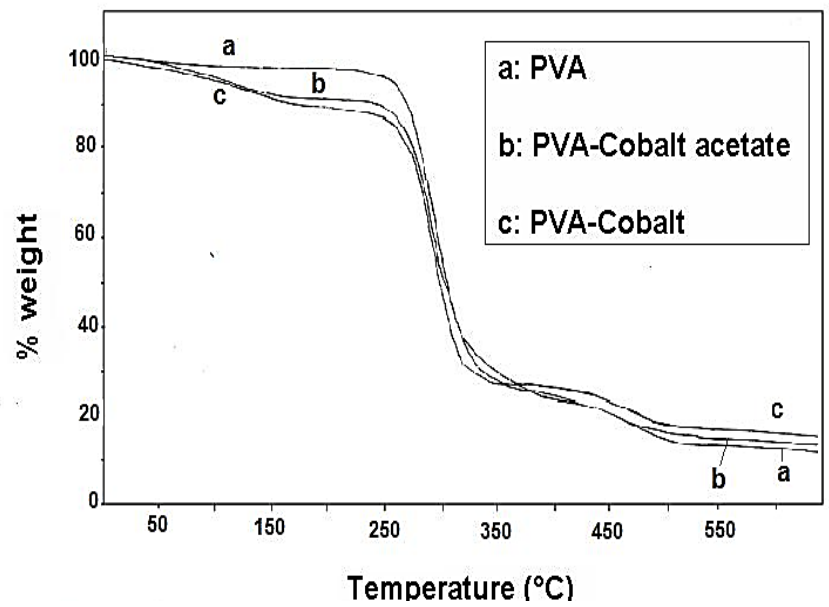

Fig. 4.TG curves for a) PVA, b) PVA-cobalt acetate composite, c) PVAcobalt composite

Cobalt acetate tertahydrate also exhibits similar decomposition behavior / pattern like that of cobalt chloride as shown in Fig. 4. The first stage decomposition is very similar to that of PVA with marginal decrease in decomposition temperature of PVA. Second step decomposition temperature however remains more or less same. Cobalt acetate when reduced to metallic cobalt in polymer matrix exhibits almost same decomposition pattern. After $550{ }^{\circ} \mathrm{C}$ onwards, a constant weight $(\sim 15 \%)$ is realized in both the cases (Table 1)

The other polymer composites based on transition metal salts like ferric chloride, ferric nitrate, and nickel nitrate included in our study show three stage decomposition behavior as discussed earlier. The decomposition patterns also remain practically same. The composites based on these salts and their metals exhibit constant weight ranging between $12-20 \%$ at $550{ }^{\circ} \mathrm{C}$ which may be due to metal oxide and some carbonaceous mass from PVA. The TG curves for these composites are included in Fig. 5, 6 and 7. The details of decomposition temperatures for different decomposition stages along with percentage weight loss are included in Table 1. Based on the above observations, it can be seen that the decomposition temperature and change in the decomposition pattern of PVA depends upon the type of metal salt / metal. Most of the composites containing hydrated salts undergo slow decomposition before PVA decomposition begins as mentioned earlier. The initial weight loss varies from salt to salt depending upon the water of crystallization associated with salt and is most probably due to thermal evaporation of water of crystallization showing appropriate weight loss. The removal of water of crystallization takes place in one step and in certain cases in more than one step. All these observations indicate that the shift in decomposition temperature of PVA takes place only after the anhydrous salt is formed. The increase in the decomposition temperature for various metal salts based composites is not very significant. However, the decomposition patterns appear to be significantly different after $300{ }^{\circ} \mathrm{C}$ showing slow degradation. This may be due to the interruption of the physical or chemical environment. The metal salts or decomposition products of metal salts like oxides create steric hindrance. It reduces thermally induced motion on the polymer backbone and scission of polymer chains improving thermal stability of polymer. This may be due to the entrapment of metal salt / metal forming coordination complex with polymer chains which requires more heat for decomposition.

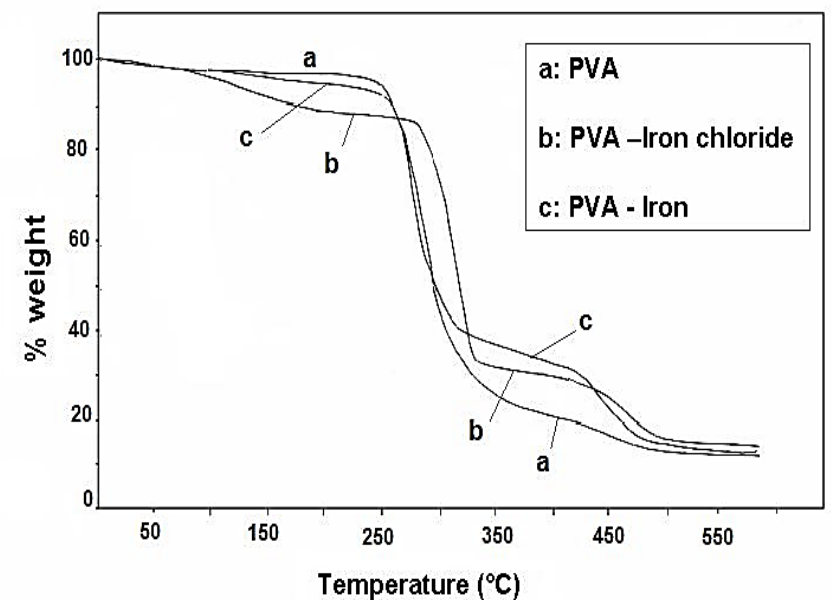

Fig. 5. TG curves for a) PVA, b) PVA-iron chloride composite, c) PVAiron composite.

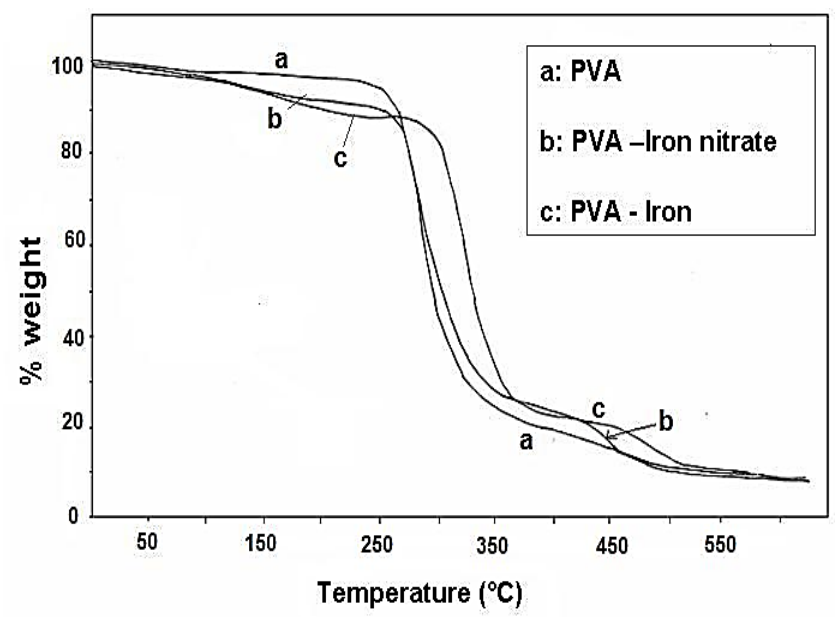

Fig. 6. TG curves for a) PVA, b) PVA-iron nitrate composite, c) PVAiron composite.

The percent weight loss at around $400^{\circ} \mathrm{C}$ (the end of first stage decomposition for pure PVA) is $75 \%$. For various metal salts doped PVA composites at the same temperature it is much less in comparison with pure PVA film. This indicates that rate of thermal decomposition in the temperature range of $220-400{ }^{\circ} \mathrm{C}$ is significantly reduced in case of various composites. The nanoparticles (metal salts / metal oxides / metals) present between the polymer chain may absorb some heat. The thermal energy now available is insufficient to maintain the same 
decomposition rate, thus slowing down the further degradation of polymer backbone.

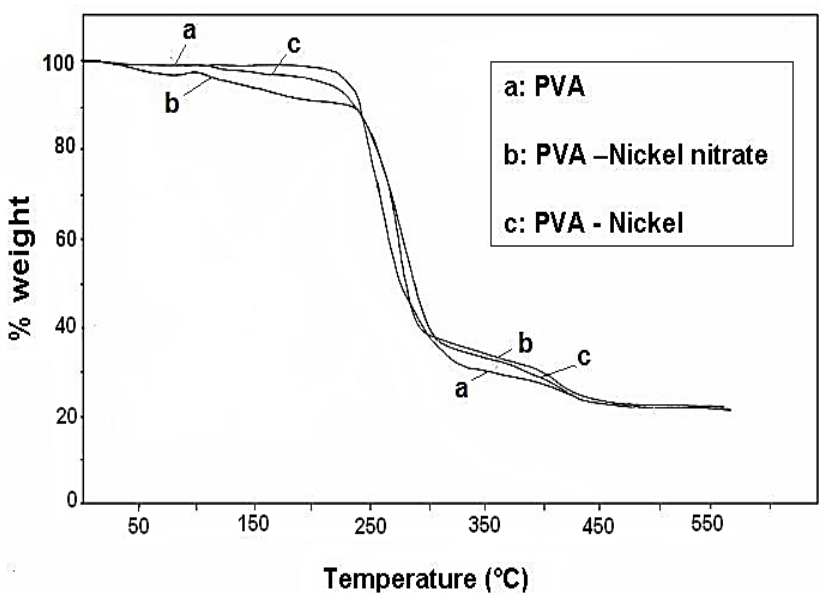

Fig. 7. TG curves for a) PVA, b) PVA-nickel nitrate composite, c) PVAnickel composite.

\begin{tabular}{|c|c|c|c|}
\hline $\begin{array}{l}\text { Composite } \\
\text { system }\end{array}$ & $\begin{array}{l}\text { Melting } \\
\text { point } \\
\left({ }^{\circ} \mathrm{C}\right)\end{array}$ & $\begin{array}{l}\text { Melting } \\
\text { enthalpy } \\
(\mathrm{J} / \mathrm{g})\end{array}$ & $\begin{array}{l}\text { Glass } \\
\text { transition } \\
\text { temperature, } \\
(\mathrm{Tg}) \\
\left({ }^{\circ} \mathrm{C}\right)\end{array}$ \\
\hline $\mathrm{PVA}+\mathrm{Co}$ & 224.7 & 99.47 & 144 \\
\hline $\begin{array}{l}\mathrm{PVA}+ \\
\mathrm{FeCl}_{3} \cdot 6 \mathrm{H}_{2} \mathrm{O}\end{array}$ & 221.3 & 26.28 & 120 \\
\hline $\mathrm{PVA}+\mathrm{Fe}$ & 210.3 & 10.43 & 82 \\
\hline $\begin{array}{l}\mathrm{PVA}+ \\
\mathrm{Fe}\left(\mathrm{NO}_{3}\right)_{3} .9 \mathrm{H}_{2} \mathrm{O}\end{array}$ & 219.5 & 96.63 & 143 \\
\hline $\mathrm{PVA}+\mathrm{Fe}$ & 205.0 & 8.24 & 83 \\
\hline $\begin{array}{l}\text { PVA+ } \\
\mathrm{CdSO}_{4} \cdot 2 \mathrm{H}_{2} \mathrm{O}\end{array}$ & 224.0 & 112.2 & 140 \\
\hline $\mathrm{PVA}+\mathrm{Cd}$ & 220.0 & 74.1 & 154 \\
\hline $\begin{array}{l}\mathrm{PVA}+ \\
\mathrm{Ni}\left(\mathrm{NO}_{3}\right)_{3} \cdot 6 \mathrm{H}_{2} \mathrm{O}\end{array}$ & 215.8 & 137.5 & 157 \\
\hline $\mathrm{PVA}+\mathrm{Ni}$ & 216 & 21.75 & 154 \\
\hline
\end{tabular}

$\mathrm{PVA}+\mathrm{CuCl}_{2}$

$222 \quad 111.46$

143

$\mathrm{PVA}+\mathrm{Cu}$

216

117

155

$\mathrm{PVA}+$

223

88.39

140

$\mathrm{CoCl}_{2} 6 \mathrm{H}_{2} \mathrm{O}$

temperature,

(Tg)

$\left({ }^{\circ} \mathbf{C}\right)$

$\mathrm{CdSO}_{4} \cdot 2 \mathrm{H}_{2} \mathrm{O}$

117

PVA +

111

PVA + point enthalp

ansition temperature $\left({ }^{\circ} \mathbf{C}\right)$

$\mathrm{CuSO}_{4} 5 \mathrm{H}_{2} \mathrm{O}$

The decomposition rate, however, depends on the nature of nanoparticles, their concentration, size, dispersion and thermal conductivity to transfer the thermal energy. However, at $550{ }^{\circ} \mathrm{C}$ a constant weight (around $14 \%$ ) is realised in case of PVA.For various composites also a constant weight is realised ranging from $(15-22 \%)$ which may due to the presence of metal oxides with some carbonaceous mass. The improvement in thermal stability may be due to restriction of polymer chain motion. In order to ascertain this possibility, the differential scanning calorimetric studies were carried out for PVA and various composites to notice the possible change in the glass transition temperature $(\mathrm{Tg})$. The $\mathrm{Tg}$ of pure PVA with molecular weight $\left(\mathrm{Mw}=1,25,000\right.$ is around $101^{\circ} \mathrm{C}$ and it is in agreement with the reported value [19]. The values for glass transition temperatures (Tg) for pure PVA and other composites are included along with their melting temperatures and melting enthalpies in Table 2. The significant shift in the glass transition temperature is noticed in case of all composites containing metal salts. When the salts are reduced to metallic form in the polymer matrix, the composites thus formed also exhibit increase in 
$\mathrm{Tg}$ with an exception of iron. The prounced increase in glass transition temperature may be due to significant decrease in mobility of polymer chains. Glass transition temperature $(\mathrm{Tg})$ however, depends on the nature of dopant, its capability to trap free radicals formed during the polymer degradation and found to be independent of dopant concentration. In the present work, the nanoparticles (metal salts / metal oxides / metals) when added to the polymer might have obstructed polymer chain mobility exhibiting an increase in $\mathrm{Tg}$. This supports our observation that the addition of nanofillers to a polymer increases the thermal stability. Lehman et al. observed improved thermal stability of composites prepared by doping nano aluminum oxide and zinc oxide in poly (methyl methacrylate) [11]. Tang et al. also made similar observations for nano-ZnO / PMMA composite [12]. According to Lehman, the increased thermal stability may be due to either by steric restriction of polymer chain motion or radical trapping of polymer chains by nanoparticles [11]. The composites based on silicate, clay, graphite as nanofillers in polypropylene, polystyrene, PMMA etc. as matrices have been reported by various researchers [13-16]. They realized improvement in thermal stability. Similar observations are made by us in the present study. However, a significant decrease in $\mathrm{Tg}$ was realized by us when iron nitrate $\left(\mathrm{Tg}, 143{ }^{\circ} \mathrm{C}\right)$ and iron chloride $\left(\mathrm{Tg}, 120^{\circ} \mathrm{C}\right.$ ) in polymer matrix were reduced to metallic iron .It appears that iron salts significantly decrease the mobility of polymer chains like other metal salts reported in Table 2 and hence exhibit increase in $\mathrm{Tg}$ value. However, when iron salts are converted to metallic iron, it fails to decrease the polymer chain mobility to that extent and exhibits decease in Tg of PVA.

\section{Conclusion}

Various polymer composites were synthesized biomimetically by embedding different transition metal salts in polyvinyl alcohol as the preorganized matrix. The metal salts in the polymer matrix were reduced to zero valent metals using sodium borohydride as the reducing agent. The thermal decomposition behavior was studied by TG and DSC analysis. An increase in the decomposition temperature of PVA was noticed when metal salts were doped into it and depends upon the nature of the metal salt and water of crystallization associated with it. Further increase in the decomposition temperature was realized when metal salts were converted into metallic form. However, such a shift in the decomposition temperature of PVA takes place only after the anhydrous salt is formed. The increase in the decomposition temperature for various composites, though not very significant, the decomposition patterns appear to be significantly different after $300{ }^{\circ} \mathrm{C}$ exhibiting slow degradation. From DSC analysis it was observed that the glass transition temperature of PVA (101 ${ }^{\circ} \mathrm{C}$ ) was found to increase for all the composites except the one containing iron. The increase in $\mathrm{Tg}$ may be due to the steric hindrance to polymer chain motion because of the presence of metal salts or decomposition products of metal salts. They reduce thermally induced motion on the polymer backbone and the number of chain scission exhibiting improved thermal stability. This may be due to the entrapment of metal salts / metals forming coordination complex through weak Vander-Waals forces requiring more heat for decomposition.

\section{Reference}

1. Krumova, M., Lopez, D., Benavenite, R., Mijangos, C., Parena , J.M . Polymer 2000,41, 9265

DOI: $10.1016 / \mathrm{S} 0032-3861(00) 00287-1$

2. Ramaraj,B., Nayak, S.K .,Yoon, K.R. J.of Appl.Polym.Sci. 2010,116, 1677.

DOI: $10.1002 / \mathrm{app} .31552$

3. Gandhi, S., Subramani, R.H.H., Ramakrishnan, T., Sivabalan, A. J Mater. Sci. 2010,45, 1694.

DOI: $10.1007 / \mathrm{s} 10853-009-4158-4$

4. Reza, R.K., Shamili , A.B., Aslani,A., Kaviani ,K. Physica B 2010 405,3100

DOI: $10.1016 / j$.physb.2010.04.021

5. Bompilwar, S.D., Kondawar, S.B., Tabhane, V.A., Kargirwar, S.R. Adv.in Appl.Sci. Res. 2010,1(1), 173.

DOI: AASR-2010-1-1-166-173

6. Xu, J., Cui, X., Zhang, J., Liang, H., Wang, H., Li , J. Bull. Mater Sci. 2008, 31, 192. DOI: $10.1007 / \mathrm{s} 12034-008-0033-1$

7. Sinha, A., Das, S.K., Rao, V., Ramachandrarao, P. Scripta mater.2001, 44, 1933.

8. Sinha, A., Agarwal, A., Das, S.K., Kumar, B.R., Rao, V., Ramachandrarao, P. J. of Mater. Sci.Lett. 2001, 20, 1569. ISSN: 0261-8028

9. Sinha, A., Das, S.K., Rao, V., Ramachandrarao, P. Current Sci. 2000,9(5), 646 .

DOI: http://tejas.serc.iisc.ernet.in/ currsci/sep102000

10. Sinha, A., Das, S.K., Rao, V., Ramachandrarao, P. J. Mater. Res. 2001, 16(5), 1357 .DOI: 10.1557/JMR.2001.0189

11. Viratyaporn, W., Lehman, R.L. J . Therm. Anal. Calorim. 2011, 103, 267.

DOI: $10.1007 / \mathrm{s} 10973-010-1051-\mathrm{y}$

12. Tang, E., Cheng, G., Ma, X. Powder Technol. 2006, 161, 14. DOI: $10.1016 / j$.powtec.2005.10.007

13. Gilman, J.W., Jackson, CL., Morgan, AB., Richard, Harris J. Chem Mater.2000, 12, 73 .

DOI: $10.1021 / \mathrm{cm} 0001760$

14. Wang, J., Du, J., Zhu, J., Wilkie, CA. Polym.Degrad. Stab.2002,77, 377

DOI: $10.1016 / \mathrm{S} 0141-3910(02) 00074-5$

15. Zhu J., Uhl FM., Morgan AB., WilkieCA.Chem. Mater. 2001,13, 4649 DOI: $10.1021 / \mathrm{cm} 010451 \mathrm{y}$

16. Wang, H., Meng, S., Xu, P., Zhong, W., Du, Q. Polym. Eng. Sci.2007, 47, 302

DOI: $10.1002 /$ pen.20708

17. Zhanhu, Guo., Di, Zhang ., Suying, Wei., Zhe, Wang .Journal of Nanoparticle Research2009, 12, 2415 DOI: $10.1007 / \mathrm{s} 11051-009-9802-\mathrm{z}$

18. Gamer, W.E., Tanner, G.A. In studies in physical and theoretical chemistry: Thermal decomposition of ionic solids; Andrew $\mathrm{K}$. Galwey; Michael E. Brown (Eds.) Elsevier: USA, 1999, Vol. 86, pp. 217-268 ISBN: 978-0-444-82437-0

19. Linga Raju, C.H., Rao, J.L., Reddy ,B .C. V., VeeraBrahmam, K. Bull .Mater .Sci.2007, 30, 21 DOI: $10.1007 / \mathrm{s} 12034-007-0038-1$ 